\title{
Risk Factors and Complications of Patients Undergoing Anesthesia
}

\author{
Samiha Mohamed Ahmed ${ }^{1}$, Mona Aly Mohamed ${ }^{2}$ \& Mona Abd Elaziem Ahmed ${ }^{3 .}$ \\ 1. Nursing Supervisor at Om El Qossur University Hospital, Egypt. \\ 2. Assistant Professor of Critical Care Nursing, Faculty of Nursing Assuit University Egypt. \\ 3. Lecturer of Critical Care Nursing, Faculty of Nursing Assuit University Egypt.
}

\begin{abstract}
Background: The incidence of perioperative complications and mortality related to anesthesia increased and involved multiple factors so, The aim of the present study is to assess of predisposing risk factors and complications for patients during anesthesia. Descriptive research design was used to conduct this study. Sitting: The study was conducted in the operating room for emergency care units at Assuit university Hospital. Sample: One hundred adult male and female patients admitted to mentioned settings and complain of risks or complications from anesthesia. Tools: Tool one: demo geographic data and general physical and medical data, Tool two: risk factors sheet, Tool three Assessment sheet of complications during anesthesia. Results: the most common risk factors of anesthesia were hypothermia $43 \%$, hypotension $79 \%$. Common complication were hypothermia in general anesthesia78\%, and hypotension in spinal anesthesia $65 \%$. Conclusion: a highly statistically significant relation was found regarding to risk factors as upper respiratory tract infections, renal impairment and the obesity, and the main complication was hypothermia. Recommendations: provide health teaching for patients before surgery and good preoperative preparation.
\end{abstract}

\section{Key Words: Anesthesia, Complications \& Risk Factors.}

\section{Introduction}

The American Society of Anesthesiologists defines anesthesiology as "The practical of medicine dedicated to the relief of pain and total care of the surgical patient before, during and after surgery" (Faircloth, 2015).

The type of anesthesia used for surgery may be local, regional, or general. Local anesthesia with sedation may be defined as moderate or procedural sedation, another term used is monitored anesthesia care. Regional anesthesia includes peripheral and central neuraxial (spinal, epidural, caudal) blocks (Joy et al., 2017).

It is important to remember that the risks of general anesthesia are not the only risks the patient should be aware of prior to their procedure, the risks of the surgery itself must be considered. Every procedure carries its own unique potential risk factors, unrelated to the anesthesia (Robertson et al., 2018).

Perioperative morbidity and mortality related to anesthesia involves multiple factors. Patient characteristics and comorbidities play a role in many of these events, highlighting the importance of preoperative screening. While optimization of patient comorbidities is not always possible, having data regarding those comorbidities can prove life-saving (Nseir et al., 2016).

The anesthesia risk might be higher if the patient has any of the following conditions: Allergies to anesthesia or a history of adverse reactions to anesthesia, Diabetes, Heart disease (angina, valve disease, heart failure or High blood pressure), Kidney problems, Lung conditions (asthma and chronic obstructive pulmonary disease, or COPD), Obesity, Obstructive sleep apnea, or neurological disorders (Arthur, 2018).

Like other medications and procedures, anesthesia use doesn't hold the record of not having any unwanted effects. The significant number of cases of anesthesia-related problems may be due to patientrelated factors, anesthesia/procedure-related factors, or both (Boytim, 2018).

Some of the most common complications of anesthesia use are: Cardiac problems like myocardial infarction (MI); Respiratory problems like pneumonia, apnea (temporary loss of respiration), and pulmonary embolism; Renal problems like renal insufficiency and failure; Neurological problems like temporary-permanent cognitive dysfunction; Development of some allergies and Death (Hui et al., 2018).

A nurse anesthetist is an advanced practice nurse who administers anesthesia for surgery or other medical procedures. Nurse anesthetists are involved in the administration of anesthesia in a majority of countries. Anesthetic nurse provides anesthesia and related care before and after surgical, therapeutic, diagnostic and obstetrical procedures (Baghai, 2016). Nurses, since they are the front-liners of health care delivery, they must be knowledgeable and skilled enough to handle such case. 
among the basic things to consider are the following: establishment of rapport and good relationship; proper identification; establishment of pre-anesthetic vital signs; provision of learning needs of the patient; provision of or ensure presence of support system; pre-operative or pre-anesthetic preparation of the patient; health education on what is expected before, during, and after the induction of anesthesia (Christopher, et al., 2018).

\section{Significance of the study}

"There should be no deaths due to anesthesia" but according to WHO some 230 million major surgical procedures are being carried out under anesthesia worldwide every years. $46.6 \%$ of all deaths were associated with an anesthesia overdose. $42.5 \%$ of deaths were due to adverse effects of anesthetics that had been administered at therapeutic dose.

From the researcher's clinical experience at Assiut university hospital it had been observed that anesthesia has many risks and complications which increase morbidity and mortality of patients. therefore this study was be carried out in an attempt to collect data that may help in planning and implementing further nursing studies for such group of patients in an attempt to reduce or eliminate risk factors for the disease.

\section{Aim of the study}

To assess predisposing risk factors and complications for patients undergoing anesthesia.

\section{Subjects \& Methods \\ Research question}

What are predisposing risk factors and complications for patients undergoing anesthesia?

\section{Research Design}

Descriptive research design was utilized to conduct the aim of this study.

\section{Setting}

The study was carried out at the operating room for emergency care unit at the Assiut university hospital.

\section{Study Subjects}

A convenient sample of 100 adult male and female patients underwent the study were admitted to the above-mentioned settings was included in the study. patients who had any risks or complications from anesthesia during operation were included in the study.

The sample was selected by using the following equation according to Steven Thompson ( 2012).

$$
n=\frac{N \times p(1-p)}{\left.\left\lfloor N-1 \times\left(d^{2} \div z^{2}\right)\right]+p(1-p)\right]}
$$

Tools of the study

Three tools were used to collect the data in this study and developed by the researcher based on reviewing of related literature.

Tool (I): Interview questionnaire assessment.

This tool is developed by the researcher and included two parts:

Part (1): Demographic data of the patient which include (age, sex, weight of patient, body mass index (BMI), and date of admission).

Part (2):General Physical and medical data of the patients which include (vital singes, investigation lab, type of operation, and medical diagnosis).

Tool (II): Risk factors which include two parts

Part (1): risk factors preoperative (obesity, age, smoking, sleep apnea, hypertension, diabetes, renal failure, hepatitis).

Part (2): risk factors during anesthesia which include (long duration of anesthesia environmental factors during operation, difficulty in tracheal intubation, high airway pressures, end bronchial intubation, aspiration, hypotension, hypertension, intramural injection, central nervous system (Dural puncture, misplaced epidural catheter, damage to epidural vessel, failure to turn on vaporizer), allergic drug reaction, over dose, Hypothermia).

Tool (III): Assessment of complications during anesthesia: hypertension, hypoxemia, hypothermia, nausea and vomiting, agitation / anxiety, aspiration, hypoventilation and others.

Operational design

It includes preparatory phase, field work phase "implementation phase" and evaluation phase.

Preparatory phase

After reviewing the recent related literatures, study tools were developed.

\section{Content validity and Reliability}

Content validity of the developed tools was carried out by a jury of 7 specialists in the field of critical care nursing and critical care medicine from Assiut University then, the tools were designed in their final format and tested for reliability using internal consistency for all the tools.

The overall reliability of the tools was tested using $(\alpha)$ Cronbach's test $(.9 \%)$ for the pilot study results.

\section{Pilot study}

A pilot study was carried out before starting of data collection to test the feasibility, applicability and the clarity of the study tools on $10 \%$ (10 patients) of the sample and the necessary modifications were done. The pilot study patients were included in the study sample. 
Field work "implementation phase"

Once the permission was granted to proceed the proposed study the researcher started data collection. Started from the first of Jun 2018 until the end of Jun 2019.

The data were collected from the admission to operating room, during operation and before exit from operation room.

Data were collected at the previously mentioned settings, the researcher went to one setting every day, introduce himself to the staff present in every sector.

All patient admitted at the previous setting and met the inclusion criteria were assessed regarding patient characteristics and clinical data by using tool one.

All patients admitted to operating room and have risk factors were assessed by using tool two.

All patients involved in the study were assessed for any complication by using tool three.

\section{Ethical considerations}

An approval was obtained from the local ethical committee and the study followed the common ethical principles in clinical research, written consent was obtained from patient or from the responsible person for the unconscious patients after explanation of the nature and the purpose of the study, patients and their families were assured that the data of this research will not be used without second permission, confidentiality of subjects data and anonymity of patients were assured, there is no risk for study subjects during application of the study and the patient had the right to refuse to participate or withdraw from the study without any rational at any time.

\section{Statistical analysis}

The collected data were coded then transformed into coding sheets. The results were checked. Then, the data were entered into statistical packing for social science (SPSS) using personal computer. Output drafts were checked against the revised coded data for typing and spelling mistakes. Finally, analysis and interpretation of data were conducted. Descriptive statistics including frequency, distribution, mean and standard deviation were used to describe different characteristics. P-value is considered significant when $\mathrm{p}<0.05$. 


\section{Results}

Table (1): socio demographic data and medical data for study sample according to type of anesthesia (n=100).

\begin{tabular}{|c|c|c|c|c|c|c|c|}
\hline \multirow{2}{*}{ Variable } & \multicolumn{2}{|c|}{$\begin{array}{c}\text { spinal anesthesia } \\
\mathbf{n}=(37)\end{array}$} & \multicolumn{2}{|c|}{$\begin{array}{c}\text { general anesthesia } \\
n=(63)\end{array}$} & \multicolumn{2}{|c|}{$\begin{array}{c}\text { Total } \\
n=(100)\end{array}$} & \multirow[t]{2}{*}{ P. value } \\
\hline & $\mathbf{n}$ & $\%$ & $\mathbf{n}$ & $\%$ & $\mathbf{n}$ & $\%$ & \\
\hline \multicolumn{8}{|l|}{ Age } \\
\hline$>30$ years & 11 & 29.73 & 12 & 19.05 & 23 & 23.00 & \multirow{4}{*}{0.449} \\
\hline $30->40$ years & 2 & 5.41 & 8 & 12.70 & 10 & 10.00 & \\
\hline 40- >50 years & 8 & 21.62 & 12 & 19.05 & 20 & 20.00 & \\
\hline$<50$ years & 16 & 43.24 & 31 & 49.21 & 47 & 47.00 & \\
\hline Mean \pm SD & \multicolumn{2}{|c|}{$47.05 \pm 20.4$} & \multicolumn{2}{|c|}{$49.54 \pm 16.66$} & \multicolumn{2}{|c|}{$48.62 \pm 18.07$} & 0.509 \\
\hline \multicolumn{8}{|l|}{ Sex } \\
\hline Male & 28 & 75.68 & 41 & 65.08 & 69 & 69.00 & \multirow{2}{*}{0.269} \\
\hline Female & 9 & 24.32 & 22 & 34.92 & 31 & 31.00 & \\
\hline \multicolumn{8}{|l|}{ BMI Level } \\
\hline $\begin{array}{l}\text { Normal or healthy weight } \\
18.5: 25 \mathrm{~kg} / \mathrm{m}^{2}\end{array}$ & 17 & 45.95 & 16 & 25.40 & 33 & 33.00 & \multirow{3}{*}{$0.004 * *$} \\
\hline Overweight $25: 30 \mathrm{~kg} / \mathrm{m}^{2}$ & 14 & 37.84 & 16 & 25.40 & 30 & 30.00 & \\
\hline Obese $>30 \mathrm{~kg} / \mathrm{m}^{2}$ & 6 & 16.22 & 31 & 49.21 & 37 & 37.00 & \\
\hline Mean \pm SD & \multicolumn{2}{|c|}{$27 \pm 7.72$} & \multicolumn{2}{|c|}{$29.02 \pm 5.89$} & \multicolumn{2}{|c|}{$28.27 \pm 6.66$} & 0.144 \\
\hline \multicolumn{8}{|l|}{ Type of operation } \\
\hline Orthopedic & 35 & 94.59 & 31 & 49.21 & 66 & 66.00 & \multirow{4}{*}{$<0.001 * *$} \\
\hline general Surgery & 2 & 5.41 & 7 & 11.11 & 9 & 9.00 & \\
\hline Cardiothoracic surgery & 0 & 0.00 & 9 & 14.29 & 9 & 9.00 & \\
\hline Brain Surgery & 0 & 0.00 & 16 & 25.40 & 16 & 16.00 & \\
\hline \multicolumn{8}{|l|}{ Medical Diagnosis } \\
\hline Appendicitis & 2 & 5.41 & 2 & 3.17 & 4 & 4.00 & \multirow{9}{*}{$<0.001 * *$} \\
\hline Cholecystitis & 0 & 0.00 & 3 & 4.76 & 3 & 4.00 & \\
\hline splenectomy & 0 & 0.00 & 2 & 3.17 & 2 & 2.00 & \\
\hline fracture Base & 0 & 0.00 & 8 & 12.70 & 8 & 8.00 & \\
\hline fracture hip & 26 & 70.27 & 8 & 12.70 & 34 & 34.00 & \\
\hline Lung injury & 0 & 0.00 & 9 & 14.29 & 9 & 9.00 & \\
\hline Spinal fracture & 0 & 0.00 & 14 & 22.22 & 14 & 14.00 & \\
\hline Subarachnoid hemorrhage & 0 & 0.00 & 8 & 12.70 & 8 & 8.00 & \\
\hline fracture Tibia & 9 & 24.32 & 9 & 14.29 & 18 & 18.00 & \\
\hline
\end{tabular}

BMI body mass index 
Table (2): Distribution of risk factor pre anesthesia for study sample $(n=100)$.

\begin{tabular}{|c|c|c|c|c|c|c|c|}
\hline \multirow[t]{2}{*}{$\begin{array}{l}\text { Types of anesthesia } \\
\text { Risk factors }\end{array}$} & \multicolumn{2}{|c|}{$\begin{array}{c}\text { spinal } \\
\text { anesthesia } \\
n=(37)\end{array}$} & \multicolumn{2}{|c|}{$\begin{array}{c}\text { general } \\
\text { anesthesia } \\
\mathbf{n}=(63)\end{array}$} & \multicolumn{2}{|c|}{ Total } & \multirow[t]{2}{*}{ P.value } \\
\hline & $\mathbf{n}$ & $\%$ & $\mathbf{n}$ & $\%$ & $\mathbf{n}$ & $\%$ & \\
\hline \multicolumn{8}{|l|}{ Cardiovascular Disease } \\
\hline Hypertension & 6 & 16.22 & 15 & 23.81 & 21 & 21.00 & 0.368 \\
\hline Ischemic heart disease & 0 & 0.00 & 1 & 1.59 & 1 & 1.00 & 0.441 \\
\hline \multicolumn{8}{|l|}{ Pulmonary Disease } \\
\hline Upper respiratory infection & 3 & 8.11 & 0 & 0.00 & 3 & 3.00 & $0.022 *$ \\
\hline \multicolumn{8}{|l|}{ Endocrine Disease } \\
\hline Diabetes & 17 & 45.95 & 31 & 49.21 & 48 & 48.00 & 0.753 \\
\hline \multicolumn{8}{|l|}{ Liver Disease } \\
\hline Hepatitis B or C & 4 & 10.81 & 9 & 14.29 & 13 & 13.00 & 0.618 \\
\hline \multicolumn{8}{|l|}{ Kidney Disease } \\
\hline Renal Failures & 11 & 29.73 & 5 & 7.94 & 16 & 16.00 & $0.004 * *$ \\
\hline \multicolumn{8}{|l|}{ Habits } \\
\hline Smoking & 28 & 75.68 & 37 & 58.73 & 65 & 65.00 & 0.086 \\
\hline Obesity & 3 & 8.11 & 15 & 23.81 & 18 & 18.00 & $0.048 *$ \\
\hline Age (elderly) & 8 & 21.62 & 21 & 33.33 & 29 & 29.00 & 0.213 \\
\hline
\end{tabular}

Table (3): Distribution of risk factor during anesthesia for study sample (n-100).

\begin{tabular}{|c|c|c|c|c|c|c|c|}
\hline & \multicolumn{2}{|c|}{$\begin{array}{c}\text { spinal } \\
\text { anesthesia } \\
(\mathbf{n}=37)\end{array}$} & \multicolumn{2}{|c|}{$\begin{array}{c}\text { general } \\
\text { anesthesia } \\
(n=63)\end{array}$} & \multicolumn{2}{|c|}{ Total } & \multirow[t]{2}{*}{ P.value } \\
\hline & $\mathbf{n}$ & $\%$ & $\mathbf{n}$ & $\%$ & $\mathbf{n}$ & $\%$ & \\
\hline Long duration of Anesthesia & 5 & 13.51 & 11 & 17.46 & 16 & 16.00 & 0.603 \\
\hline \multicolumn{8}{|l|}{ Airway } \\
\hline Difficulty in tracheal intubation & 0 & 0.00 & 26 & 41.27 & 26 & 26.00 & $<0.001 * *$ \\
\hline \multicolumn{8}{|l|}{ Respiratory } \\
\hline end bronchial intubation & 0 & 0.00 & 4 & 6.35 & 4 & 4.00 & 0.118 \\
\hline Aspiration & 0 & 0.00 & 7 & 11.11 & 7 & 7.00 & $0.036 *$ \\
\hline \multicolumn{8}{|l|}{ Cardiovascular } \\
\hline Hypotension & 26 & 70.27 & 53 & 84.13 & 79 & 79.00 & 0.100 \\
\hline Hypertension & 3 & 8.11 & 3 & 4.76 & 6 & 6.00 & 0.496 \\
\hline \multicolumn{8}{|l|}{ Central nervous system } \\
\hline Misplaced epidural catheter & 3 & 8.11 & 0 & 0.00 & 3 & 3.00 & $0.022 *$ \\
\hline \multicolumn{8}{|l|}{ Anesthesia Drug related } \\
\hline Hypothermia & 25 & 67.57 & 18 & 28.57 & 43 & 43.00 & $<0.001 * *$ \\
\hline \multicolumn{8}{|l|}{ Others } \\
\hline Bleeding & 0 & 0.00 & 5 & 7.94 & 5 & 5.00 & \multirow{4}{*}{0.083} \\
\hline Bradycardia & 2 & 5.41 & 3 & 4.76 & 5 & 5.00 & \\
\hline Bradycardia, apnea & 2 & 5.41 & 0 & 0.00 & 2 & 2.00 & \\
\hline cardiac arrest & 0 & 0.00 & 3 & 4.76 & 3 & 3.00 & \\
\hline
\end{tabular}


Table (4): Comparison between two type of anesthesia according to complications.

\begin{tabular}{|c|c|c|c|c|c|}
\hline & \multicolumn{2}{|c|}{ spinal anesthesia $(n=37)$} & \multicolumn{2}{|c|}{ general anesthesia $(n=63)$} & \multirow{2}{*}{ P.value } \\
\hline & n & $\%$ & $\mathbf{n}$ & $\%$ & \\
\hline \multicolumn{6}{|c|}{ Hyperthermia } \\
\hline No & 37 & 100.00 & 62 & 98.41 & \multirow{2}{*}{0.441} \\
\hline Yes & 0 & 0.00 & 1 & 1.59 & \\
\hline \multicolumn{6}{|c|}{ Hypothermia } \\
\hline No & 8 & 21.62 & 51 & 80.95 & \multirow{2}{*}{$<0.001 * *$} \\
\hline Yes & 29 & 78.38 & 12 & 19.05 & \\
\hline \multicolumn{6}{|c|}{ Hypotension } \\
\hline No & 9 & 24.32 & 22 & 34.92 & \multirow{2}{*}{0.269} \\
\hline Yes & 28 & 75.68 & 41 & 65.08 & \\
\hline \multicolumn{6}{|c|}{ Hypertension } \\
\hline No & 34 & 91.89 & 62 & 98.41 & \multirow{2}{*}{0.108} \\
\hline Yes & 3 & 8.11 & 1 & 1.59 & \\
\hline
\end{tabular}

Table (5): Distribution of other complications according to type of anesthesia.

\begin{tabular}{|l|c|c|}
\hline \multicolumn{1}{|c|}{ Other complication } & $\mathrm{n}$. & $\%$ \\
\hline spinal anesthesia & & \\
\hline spinal cord injury & 3 & 7.7 \\
\hline general anesthesia & & 23.0 \\
\hline Aspiration & 14 & 6.6 \\
\hline Nausea \& vomiting & 4 & 1.6 \\
\hline Prolonged ventilation & 1 & 1.6 \\
\hline Others & & 1.6 \\
\hline Bleeding & 1 & 1.6 \\
\hline Bradycardia & 1 & 6.6 \\
\hline Coma & 1 & 1.6 \\
\hline Shock & 4 & \\
\hline Sudden cardiac arrest & 1 & \\
\hline
\end{tabular}

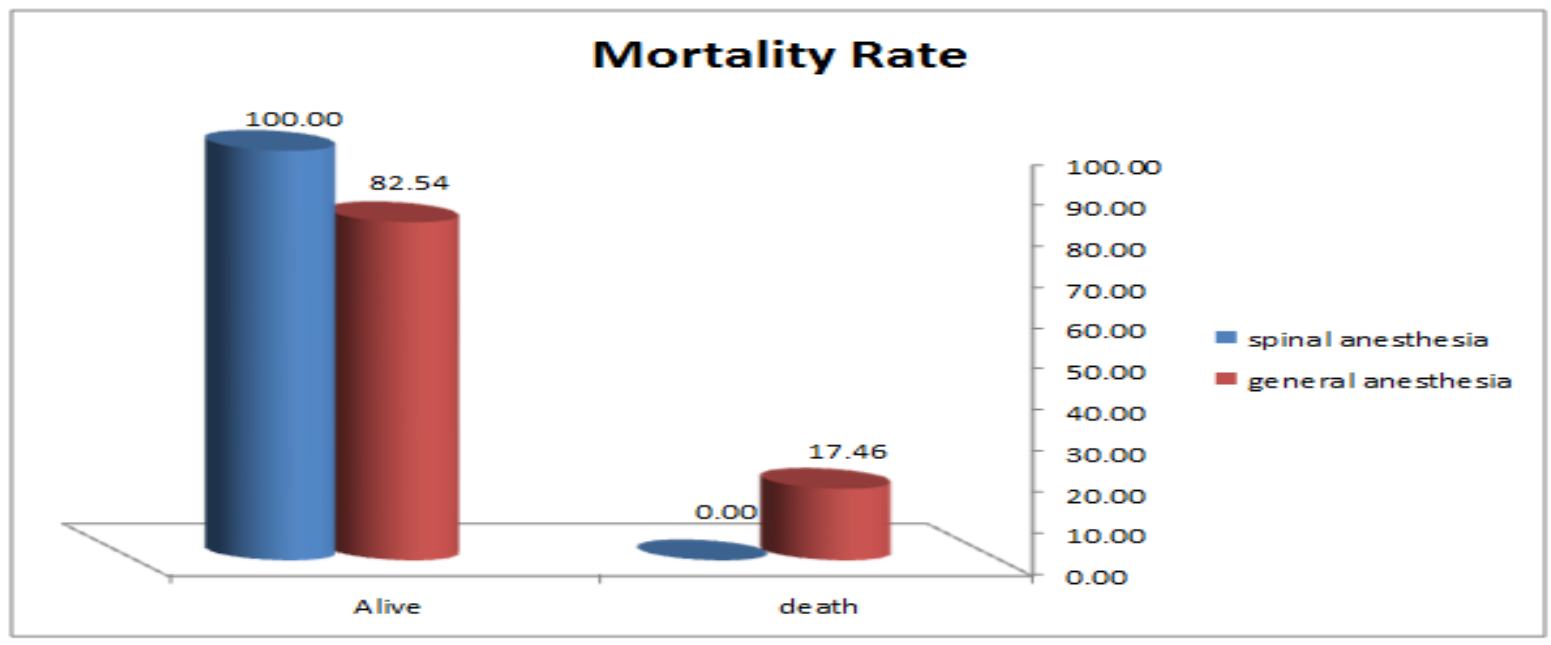

Figure (1): Comparison between two type of anesthesia according to mortality rate. 
Table (6): Correlation Co- efficient between risk factors pre anesthesia and socio demographic data according to type of anesthesia.

\begin{tabular}{|c|c|c|c|c|c|c|}
\hline & \multicolumn{6}{|c|}{ Demographic data } \\
\hline & \multicolumn{3}{|c|}{ Spinal anesthesia } & \multicolumn{3}{|c|}{ General anesthesia } \\
\hline & \multicolumn{6}{|c|}{ Pre anesthesia } \\
\hline & Age & Sex & BMI & Age & Sex & BMI \\
\hline & $\mathbf{r}$ & $\mathbf{R}$ & $\mathbf{r}$ & $\mathbf{r}$ & $\mathbf{R}$ & $\mathbf{r}$ \\
\hline Hypertension & 0.104 & 0.263 & $.517^{* * *}$ & 0.042 & 0.099 & -0.178 \\
\hline Upper respiratory infection & $.392^{*}$ & $.524^{* *}$ & $.391^{*}$ & & & \\
\hline Diabetes & $.567^{* *}$ & 0.236 & 0.199 & -0.104 & 0.128 & 0.071 \\
\hline Hepatitis B or C & 0.148 & -0.197 & $-.467-{ }^{* * *}$ & -0.031 & -0.094 & 0.117 \\
\hline Renal Failures & $.468^{* *}$ & 0.045 & 0.200 & -0.058 & -0.082 & -0.063 \\
\hline Smoking & -0.303 & $-1.000-{ }^{*}$ & 0.053 & 0.182 & $-.291-^{*}$ & -0.106 \\
\hline Obesity & $.392^{*}$ & $.524^{* *}$ & $.391^{*}$ & 0.031 & 0.061 & 0.172 \\
\hline Age (elderly) & $.687^{* *}$ & $.620^{* * *}$ & -0.080 & $.317^{*}$ & -0.131 & 0.073 \\
\hline
\end{tabular}

Table (7): Correlation Co- efficient between risk factors during anesthesia and socio demographic data according to type of anesthesia.

\begin{tabular}{|c|c|c|c|c|c|c|}
\hline & \multicolumn{6}{|c|}{ During anesthesia } \\
\hline & \multicolumn{3}{|c|}{ Spinal anesthesia } & \multicolumn{3}{|c|}{ General anesthesia } \\
\hline & Age & Sex & BMI & Age & Sex & $\mathrm{BMI}$ \\
\hline & $\mathbf{r}$ & $\mathbf{r}$ & $\mathbf{r}$ & $\mathbf{r}$ & $\mathbf{r}$ & $\mathbf{R}$ \\
\hline Long duration of Anesthesia & $-.551-^{* * * 6}$ & -0.224 & -0.297 & -0.185 & 0.196 & -0.145 \\
\hline Difficulty in tracheal intubation & & & & 0.173 & -0.011 & 0.015 \\
\hline End bronchial intubation & & & & -0.083 & -0.056 & 0.063 \\
\hline Aspiration & & & & -0.242 & 0.166 & -0.169 \\
\hline Hypotension & -0.184 & -0.045 & $-.434-^{* * *}$ & 0.117 & -0.208 & 0.070 \\
\hline Hypertension & 0.000 & -0.168 & 0.112 & -0.120 & 0.177 & -0.058 \\
\hline Misplaced epidural catheter & -0.252 & -0.168 & 0.307 & & & \\
\hline Hypothermia & 0.120 & $.393^{*}$ & 0.005 & -0.029 & -0.047 & 0.045 \\
\hline
\end{tabular}

Table (1): Represents the Sociodemographic and clinical data of patients underwent the surgical operations; it was noticed that there was a significant difference between the both groups as regard to body mass index with, type of operation and medical diagnosis with $\mathrm{p}$ value (0.004 and 0.001) respectively. In relation to age and sex there was no significant difference.

Table (2): Illustrate the risk factors for pre anesthesia incidents and show that there were a highly significant differences between both groups in relation to upper respiratory tract infections, renal impairment and the obesity with $\mathrm{p}$ value $(0.022$, 0.004 and 0.048 ) respectively with no significant difference related to other risk factors included in the study.

Table (3): Clarifies that there was a highly significant difference between the both groups in relation to hypothermia and misplaced epidural catheter with $\mathrm{p}$ value $(0.001 \& 0.022)$ respectively. But, for the general anesthesia group this table revealed that for the airway management there was significant difference related to aspiration after intubation with $\mathrm{p}$ value 0.036 .

Table (4): Illustrate that there was significant difference related to the hypothermia among the both groups with $\mathrm{p}$ value 0.001 and there was no statistical difference related to hyperthermia, hypotension and hypertension.

Table (5): Shows the incidence of the complications occurred with the both types of anesthesia and indicate that the most common complication in general anesthesia were aspiration and shock but for the spinal group the most common complications was the spinal cord injury.

Figure (1): Show the mortality rate incidence between the spinal and general anesthesia groups that 
there was significant difference among the both groups in relation to death with $\mathrm{p}$ value 0.004 . the rate of mortality higher in general than spinal group.

Table (6): Revealed that there was no statistical significant between risk factor and socio demographic data according to type of anesthesia "pre anesthesia" except between sex and renal failure in spinal anesthesia that among spinal anesthesia group. While general anesthesia group, there were statistical significant difference only between age and both hypertension and obesity.

Table (7): Showed that there was no statistical significant between risk factor and socio demographic data according to type of anesthesia "during anesthesia" except among spinal anesthesia group ages and hypertension and between their BMI and hypothermia. While general anesthesia group, there were significant difference between BMI and difficulty in tracheal intubation and hypothermia.

\section{Discussion}

Regarding demographic data in relation to age and sex there was a significant difference. In addition the result found that majority of both groups were males and aged 50 years old and more. When comparing the patient in relation to the type of anesthesia used the current study revealed that there is no significant difference between both groups regarding their age.

This agreed with Cameron et al., (2016) who found the age of patients were more than 50 years old. But Barry, \& Thompson, (2018) found that patents mean age was 67.5 years old. Prior research has shown that severity of illness is more important than age on patients' prognosis, and aggressive treatment strategies are not less cost-effective when provided to older patients (Schumacher et al., 2017).

These results disagree with (Gonano, et al., 2016) who said that the spinal group was older than the general anesthetic group.

Whippey et al., (2016) concluded that the only factors associated with mortality changes were patient age. Although age is a consistent risk factor for the incidence of illness, its independent association with mortality after accounting for risk, severity, and comorbidity is not consistent (Ishii et al., 2016).

Regarding to the patient sex, the present study demonstrated that the majority of the both groups were males' patients with no significant difference between the both groups in relation to sex and this result is supported by the study of (Kadirehally, et al., 2017) who noticed that there was no any statistical significant difference between both groups related to sex.
This compatible with Klein et al., (2017) who found no significant difference between both sexes which compatible with the result of the existing study. In this line Karaaslan \& Yalin, (2019) found that male: female ratio in admitted patients who undergoing anesthesia was $1: 2$

Regarding patients underwent the surgical operations; it was noticed that there was a significant difference between the both groups as regard to body mass index with, type of operation and medical diagnosis with $\mathrm{p}$ value $(0.004$ and 0.001$)$ respectively.

The current study mentioned that according to the body mass index, the general anesthesia is supposed more than the spinal to avoid any patient injury and the difficult access to the site. About half of the studied population who were obese $>30 \mathrm{~kg} / \mathrm{m}^{2}$ underwent general anesthesia compared to only one sixth of the patient went spinal anesthesia with s high significant difference. And this result was supported with the study of Moslemi \& Rasooli, (2017) who reported that there was significant difference between the both groups related to the body mass index.

Regarding type of operation was orthopedic to treat fracture hip was the main type found in our study that because out sitting was the emergency operation where the main patients were trauma patents.

In the same line Alsaif, et al., (2018) recorded that there was a significant difference between the both groups in relation to the type of anesthesia used.

Total hip surgery is considered one of the most successful orthopedic procedures, and more than one million operations are performed each year worldwide ${ }^{1}$. Historically, general anesthesia has been the gold standard for major hip surgery (Katz et al., 2017). However, the optimal anesthetic technique remains debated.

According to the body temperature changes, the current study showed that more than triple quarter of the patient underwent spinal anesthesia suffering from hypothermia with significant difference between both groups and this result is confused with the results of (Szmuk, et al., 2018) who illustrated that the patient with spinal anesthesia require less time to be rewarmed.

The present study demonstrated that about one quarter of the studied population suffered from aspiration as complication of the general anesthesia this result and this result disagreed with (Kluger \& Short, 2017) who reported that there was no significant difference related to aspiration between the studied patient and about $7 \%$ of patients underwent general anesthesia express nausea and vomiting and this result is confirmed with the results of (Ebied, et al., 2016) who showed that the nausea 
and vomiting no statistically difference among both groups.

As regard for the anesthesia time the present study showed that the anesthetic time of the general anesthetic time is lower than the spinal anesthetic time but with no significant difference between the both groups related to anesthetic time and this result matched with the result of (Sedat, et al., 2016) who reported that the general anesthesia time is lower than this of spinal anesthesia.

Certain health factors can increase surgery and anesthesia complications. Physician anesthesiologists help lower these risks by examining the patient's medical history and conducting a health assessment before surgery, and by monitoring and supervising the care during and after surgery.

In relation to these risk factors, the present study mentioned that the most statistically significant difference was related to upper respiratory tract infection and group of renal diseases especially the renal failure for the patients underwent spinal anesthesia as he noticed about one fifth of these patients suffering from complication and these results were in the same line with (Argyro, et al., 2015) who reported that chronic obstructive pulmonary diseases, upper respiratory infections and renal diseases were highly significant difference between the groups. But, disagree with the current study as he showed that cardiovascular diseases also were a risk factor for anesthesia complication.

As regarding for obesity, this result agreed with the study of (Fields, et al., 2015) who confirmed that obesity and heavy smoking were considered risk factors for anesthesia complications.

Regarding to postoperative mortality rate, the present study mentioned that that there were no death cases reported with spinal anesthesia and about one fifth of patients underwent general anesthesia died and these results are conflicted with the results of Melamed et al., (2016) who illustrated that the mortality associated with spinal was higher than the mortality rate in case of the general anesthesia.

In this respect Boodle, (2017) found one third of the studied patients died post operatively after addition to ICU.

The present study revealed that there was no statistical significant between risk factor and socio demographic data according to type of anesthesia "pre anesthesia" except between sex and renal failure in spinal anesthesia that among spinal anesthesia group. While general anesthesia group, there were statistical significant difference only between age and both hypertension and obesity.
This not greed with O'Donnell et al., (2018) who found no significant difference between the two anesthesia types and acute renal failure.

Regarding the relation between anesthesia complication and hypertension, mentioned that increasing blood pressure consider a strong risk for elevated perioperative mortality and morbidity.

The present study showed that there was no statistical significant between risk factor and socio demographic data according to type of anesthesia "during anesthesia" except among spinal anesthesia group ages and hypertension and between their BMI and hypothermia.

This match with Adhockery et al., (2016) who stated that there was a positive relation between obesity as a risk for anesthesia complication than the normal weight patients.

This not match with Disma et al., (2018) who found that increased incidence of intraoperative hypotension that has been described with general anesthesia compared with neuraxial anesthesia.

This result agreed with Davidson et al., (2016) who found that there was a strong relation between patients' ages and the risk of perioperative complications.

While general anesthesia group, there were significant difference between BMI and difficulty in tracheal intubation and hypothermia. In this respect, Yao et al., (2019) mentioned that increases weight and BMI make it difficult to insert tracheal intubation for general anesthesia which confirm our study results. Chitturi et al., (2018) focused on the obese patients who planned to surgery should thoroughly evaluated by medical condition check up to avoid the risk of post- operative mortality.

\section{Conclusion}

A highly statistically significant relation was found regarding to risk factors as upper respiratory tract infections, renal impairment and obesity. The main complication was hypothermia.

\section{Recommendations}

Provide health teaching for patients before surgery and good preoperative preparation.

\section{References}

1. Adhikary, S., Liu, W., Memtsoudis, S., Davis III, C., \& Liu, J., (2016): Body mass index more than $45 \mathrm{~kg} / \mathrm{m} 2$ as a cutoff point is associated with dramatically increased postoperative complications in total knee arthroplasty and total hip arthroplasty. The Journal of arthroplasty, 31(4), 749-753 
2. Alsaif A., Saleh A., Farhan A., Faris A., \& Abdullah A., (2018): Patient satisfaction and experience with anesthesia: A multicenter survey in Saudi population, Saudi J Anesthesiology, 12(2): 304-310.

3. Argyro P., Vassilios T., George V., Zacharoulis D., Konstantinos T., (2015): Depth of Anesthesia as a Risk Factor for Perioperative Morbidity, Anesthesiology Research and Practice.

4. Arthur M., (2018): Crisis Management in the Perioperative Setting, Anesthesiology CA-1 Pocket Survival Guide, Oxford University Press.

5. Baghai A., (2016): to what extent, if any, does an increase in scope of practice restrict ent ry into practice, sunrise application Arizona ass ociation of nurse anesthetists.

6. Barry R., \& Thompson E., (2018): Outcomes after rib fractures in geriatric blunt trauma patients. The American Journal of Surgery, 215(6), 1020-1023

7. Bowdle T., (2017): Is Etomidate Sedation Associated With Excess Mortality in Intensive Care Unit Patients? What Is the Evidence? Anesthesia \& Analgesia, 125(2), 713

8. Boytim J., (2018): Factors Contributing to Perioperative Medication Errors: A Systematic Literature Review, AORN Journal.

9. Cameron J., Chu L., Matte A., Tomlinson G., Chan L., Thomas C., \& Ferguson N., (2016): One-year outcomes in caregivers of critically ill patients. New England Journal of Medicine, 374(19), 1831-1841

10. Chitturi S., Wong V., Chan W., Wong G., Wong S., Sollano J., \& Kim, S., (2018): The Asia-Pacific Working Party on Non-alcoholic Fatty Liver Disease guidelines 2017-Part 2: Management and special groups. Journal of gastroenterology and herpetology, 33(1), 86-98

11. Christopher M., Daniel A., Brian J., Franklin C., Dean F., (2018): Preoperative Evaluation, manual on professional liability, American Society of Anesthesiologists, pp 1-29.

12. Davidson A., Disma N., De Graaff J., Withington D., Dorris L., Bell G., \& Hardy P., (2016): Neurodevelopmental outcome at 2 years of age after general an aesthesia and awake-regional an aesthesia in infancy (GAS): an international multicenter, randomized controlled trial. The Lancet, 387(10015), 239250.

13. Disma N., Clunies-Ross N., \& Chalkiadis G., (2018): Is spinal an aesthesia in young infants really safer and better than general an aesthesia?. Current

Opinion

in Anesthesiology, 31(3), 302-307.

14. Ebied R., Mohamed Z., Hanan F., Mohamed M., \& Yasser M., (2016): Comparative study between continuous epidural anesthesia and continuous Wiley Spinal ${ }^{\circledR}$ anesthesia in elderly patients undergoing TURP, semantic scholar.

15. Faircloth C., (2015): American Association of Nurse Anesthetists' , Nurse Anesthetists-part 3Acumpuncture, 83(4) :pp289-292.

16. Fields A., Dietrich J., Buterbaugh K., \& Moucha C., (2015): Short-term complications in hip fracture surgery using spinal versus general anesthesia. Injury, 19-23

17. Gonano C., Leitgeb U., Sitzwohl C., Ihra G., Weinstabl C., (2016): Spinal Versus General Anesthesia for Orthopedic Surgery: Anesthesia Drug and Supply Costs, Anesthesia \& Analgesia, 102(2):524-529.

18. Hui, S., Rebecca L., \& Ruth E., (2018): Frailty and anesthesia - risks during and post-surgery, Local Regional Anesthesia, 11: 61-73.

19. Ishii K., Makita T., Yamashita H., Matsunaga S., Akiyama D., Toba K\& Hara T., (2016): Total intravenous anesthesia with propofol is associated with a lower rate of postoperative delirium in comparison with sevoflurane anesthesia in elderly patients. Journal of clinical anesthesia, 33, 428431.

20. Joy S., Blas C., Christopher S., \& Lebron C., (2017): Life-threatening perioperative anesthetic complications: major issues surrounding perioperative morbidity and mortality, The American Association for the Surgery of Trauma, BMJ Journal, 2(1).

21. Kadirehally B., Rani D., Harave S., Gowda V., \& Chanappa M., (2017): Fears and Perceptions Associated with Regional Anesthesia: A Study from a Tertiary Care Hospital in South India, Anesthesia Essays Res, 11(2): 483-488.

22. Karaaslan E., \& Yalin M., (2019): Anesthesia management of open tracheostomy patients: A single center experience. Medicine, 8(3), 741-5.

23. Katz J., Winter A., \& Hawker G., (2017): Measures of the appropriateness of elective orthopaedic joint and spine procedures. JBJS, 99(4), e15.

24. Klein G, Posner J, Levine H, \& Hartzband M (2017): Same day total hip arthroplasty performed at an ambulatory surgical center: 90day complication rate on 549 patients. The Journal of arthroplasty, 32(4), 1103-1106 
25. Kluger M., \& Short T, (2017): Aspiration during an aesthesia: a review of 133 cases from the Australian An aesthetic Incident Monitoring Study (AIMS), Volume54(1):19-26

26. Melamed R., Boland L., Normington J., Prenevost R., Hur L., Maynard L., \& Huguelet J., (2016): Postoperative respiratory failure necessitating transfer to the intensive care unit in orthopedic surgery patients: risk factors, costs, and outcomes. Perioperative Medicine, 5(1), 19.

27. Moslemi F., \& Rasooli S., (2017): Comparison of Spinal Versus General Anesthesia for Cesarean Delivery in Patients with Severe Preeclampsia, Journal of Medical Sciences, 7 (6):1044-1048.

28. Nseir S., Povoa P., Salluh J., (2016): Is there a continuum between ventilator-associated tra chew bronchitis and ventilator-associated pneumonia? Intensive Care Med, 42:1190.

29. O'Donnell C., McLaughlin L., Patterson C., Clarke M., McCourt K., McBrien M., \& Shields, M., (2018): Perioperative outcomes in the context of mode of an aesthesia for patients undergoing hip fracture surgery: systematic review and meta-analysis. British journal of anaesthesia, 120(1), 37-50

30. Robertson S., Gogolski S., Peter P., Shafford H., Jennifer S., (2018): AAFP Feline Anesthesia Guidelines, Journal of Feline Medicine and Surgery,20(7): 602-634.

31. Schumacher R., Müri R., \& Walder B., (2017): Integrated Health Care Management of Moderate to Severe TBI in Older Patients-A Narrative Review. Current neurology and

32. Sedat S., Ahmet E., \& Davut D., (2016): The Effects of Single-Dose Rectal Midazolam Application on Postoperative Recovery, Sedation, and Analgesia in Children Given Caudal Anesthesia Plus Bupivacaine, Journal of Biomedicine and Biotechnology,

33. Steven K., Thompson (2012): sample size, P. P :59-60.

34. Szmuk P., Tiberiu E., Daniel I., Arnold S., Daniel G., (2018): Spinal Anesthesia Speeds Active Postoperative Rewarming, Anesthesiology, 87:1050-1054.

35. Whippey A., Kostandoff G., Cheng J., Thabane L., \& Paul J., (2016): Predictors of unanticipated admission following ambulatory surgery in the pediatric population: a retrospective case-control study. Pediatric Anesthesia, 26(8), 831-837.

36. Yao W., Li S., Yuan Y., Tan H., Han N., Sultana R., \& Sng B., (2019): Comparison of
Supreme laryngeal mask airway versus endotracheal intubation for airway management during general anesthesia for cesarean section: a randomized controlled trial. BMC anesthesiology, 19(1), 123. 